\title{
The Size Premium: What Role Does Macroeconomic Risk Play?
}

Link to publication record in Manchester Research Explorer

\section{Citation for published version (APA):}

Cho, S. (2012). The Size Premium: What Role Does Macroeconomic Risk Play? (SSRN working paper; No. 1969828).

\section{Citing this paper}

Please note that where the full-text provided on Manchester Research Explorer is the Author Accepted Manuscript or Proof version this may differ from the final Published version. If citing, it is advised that you check and use the publisher's definitive version.

\section{General rights}

Copyright and moral rights for the publications made accessible in the Research Explorer are retained by the authors and/or other copyright owners and it is a condition of accessing publications that users recognise and abide by the legal requirements associated with these rights.

\section{Takedown policy}

If you believe that this document breaches copyright please refer to the University of Manchester's Takedown Procedures [http://man.ac.uk/04Y6Bo] or contact uml.scholarlycommunications@manchester.ac.uk providing relevant details, so we can investigate your claim.

\section{OPEN ACCESS}




\title{
The Size Premium: What Role Does Macroeconomic Risk Play?
}

\author{
Sungjun $\mathrm{Cho}^{1}$
}

\section{This version: June 25, 2012}

${ }^{1}$ Correspondence Information: Sungjun Cho is with Manchester Business School, Crawford House, University of Manchester, Oxford Road, Manchester M13 9PL, UK. Tel.:+44(0)161 306 3483;fax:+44(0)161 275 4023;Email address: sungjun.cho@mbs.ac.uk 


\begin{abstract}
The size effect is alive well but visible only when the economy is in a high volatility regime. This result is robust across different sample periods and model specifications. Independent business cycle and volatility regimes are identified from bivariate regime switching models of the industrial production growth and the small firm premium (SMB). The SMB factor is not priced by the market excess return (RMRF) and the value premium (HML) in the high volatility regime rather than in a recession regime. An economic rational for the size premium is provided through the capital market imperfection hypothesis.
\end{abstract}

Keywords: The Size Premium, Volatility Regime Switching, Capital Market Imperfections

JEL Classification: E32, E52, G12 


\section{Introduction}

Banz (1981) first reports that small-capitalization firms on the New York Stock Exchange (NYSE) earned higher average returns than is predicted by the CAPM from 1936 to 1975. Fama and French (1993) adopt this empirical fact and develop their three-factor asset pricing model (FF) with the market excess return (RMRF) and two mimicking portfolios based on market capitalization (SMB) and book-to-market (HML). The FF model has become an industry standard because it can explain the average return variations across portfolios formed on many different characteristics. Fama and French interpret their two mimicking portfolios as risk factors capturing a risk premium for the relative distress of firms in the context of ICAPM while the underlying economic source of the risk premium has not yet fully understood.

van Dijk (2011) surveys the literature on the size effect and identifies two seemingly contradictory developments in research on the size effect since the late 1990s; many theoretical models are developed to explain the size effect (e.g. Berk, Green, and Naik (1999)), but the size effect has disappeared since the early 1980s according to most of the empirical studies. For example, Horowitz, Loughran, and Savin (2000) report that small firms did not earn higher average realized returns than big firms during the 1980s and 1990s. Schwert (2003) asserts that "it seems that the small-firm anomaly has disappeared since the initial publication of the papers that discovered it." It is well known that if the anomalies are a result of data snooping bias, these are expected to disappear in the data soon after they have been reported. If this is indeed the case, the SMB factor should not be interpreted as a systematic risk factor to generate a risk premium in the rational asset pricing model. It would be puzzling why Fama and French still keep their SMB factor in explaining the cross-section of stock returns.

Interestingly, Hou and van Dijk (2010) argue that the size effect exists in ex ante expected returns but might not be visible in realized returns. They show that small 
firms experience large negative profitability shocks after the early 1980s, while big firms experience large positive shocks. After filtering out this noise, they find a robust size effect in expected returns. However, they do not provide the underlying causes of the size effect, and ask for a revival of academic research on the issue. Based on the careful summary of the literature, van Dijk (2011)(p3263) argues "it is premature to conclude that the size effect has gone away...whether and how existing models can be reconciled with known patterns in the returns on small and large stocks is not clear".

In this paper, I document a new stylized fact on the size effect to resolve this seemingly puzzling issue. I find that the SMB factor earns a significant independent risk premium only in uncertain macroeconomic states, even though it has a zero risk premium on average. This result is robust across different time periods and model specifications. Motivated by Lettau, Ludvigson, and Wachter (2008), I employ several bivariate regime switching models for the growth rate of industrial production and the SMB factor to identify two independent switching state variables; one of the two regime switching state variables captures fairly well a business cycle regime while the other captures a volatility regime. I show that the SMB factor is important as a pricing factor only when the economy is in a high volatility regime while the factor is redundant in other regimes.

In a related study, Perez-Quiros and Timmermann (2000) find that the size premium would be present only in a recession regime by estimating the conditional distribution of stock returns using several financial or macro variables with two regime specifications, which they interpret as business cycle regimes. However, because they identify two regimes primarily based on stock returns, their estimated regimes sometimes seem to mix high volatility regimes in the stock market (e.g. 1987 stock market crash) with a recession regime.

Instead I use the joint distribution of the growth rate of industrial production and the SMB to estimate independent mean and volatility regimes. The estimated mean and 
volatility regimes capture stylized facts on the economy quite accurately. The estimated mean regimes are closely tracking business cycle patterns, and the volatility regimes pick up the so-called great moderation since 1984. While it is often said that recessions coincides with the high volatility regimes, I find that the correlation of two are quite small (0.2) since July 1963.

I claim that the so-called "Great Moderation" coined by Ben Bernanke has been effectively masked the size effect until recently. Kim and Nelson (1999) and McConnell and Perez-Quiros (2000) show that US output volatility had declined substantially in the early 1980s. Interestingly, this period coincides with the initial publication of the size effect. However, the size effect has been resurrected since the recent financial crisis coupled with uncertain economic environment. For example, the average monthly size premium was $1.615 \%$ during 2008 .

Perez-Quiros and Timmermann (2000), based on the imperfect capital market theories, claim that small firms with little collateral do not have the same access to credit markets that are enjoyed by large firms. The high returns to small firms (SMB) might be compensation for taking this credit-related risk because small firms are more affected by tight credit market conditions in a recession regime.

However, in well-developed financial markets such as U.S.A., perhaps recession itself would not hamper raising capitals for the small-sized firms unless it coincides with the high uncertainty. I argue that even in the recession if it is not companied with severe economic uncertainty, the capital market would function well. Only high macroeconomic volatility regime would discourage the provision of credit by increasing uncertainty about prospective returns and exposing banks to potentially large losses. Investors would ask compensation for this systematic risk to credit-constrained small-size firms in high volatility regime. Indeed the results in this paper support the implication. I find that the size premium would be present only in a high volatility regime from time-series asset 
pricing tests based on the Fama-French three-factor model.

The rest of the paper is organized as follows: Section 2 discusses the empirical models; Section 3 describes the data; Section 4 presents the estimation results; and Section 5 concludes.

\section{Empirical Models}

This section discusses empirical models employed to test the existence of the size premium; the first subsection briefly describes a regime switching model with mean and volatility regimes for the industrial production growth and the second subsection explains how to test whether a factor is redundant. The third subsection combines these two models and presents the main econometric specifications.

\subsection{Regime Switching Model}

Consider a time-series of observations on the industrial production $\left(Y_{t}\right)$ and let lowercase letters denote log variables, that is, the growth rate of industrial production becomes $\Delta y_{t} \equiv \log Y_{t} / Y_{t-1}$. A regime switching model of $\Delta y_{t}$ takes the form,

$$
\Delta y_{t}=\mu\left(S_{t}\right)+\varepsilon_{t}, \varepsilon_{t} \sim N\left(0, \sigma^{2}\left(V_{t}\right)\right)
$$

where $S_{t}$ and $V_{t}$ are latent state variables for the states of mean and variance.

I assume that the probability of changing mean states is independent of the probability of changing volatility regimes following Lettau, Ludvigson, and Wachter (2008). It follows that there are two mean regimes, $\mu_{t} \equiv \mu\left(S_{t}\right) \in\left\{\mu_{l}, \mu_{h}\right\}$ and two volatility regimes, $\sigma_{t} \equiv \sigma\left(V_{t}\right) \in\left\{\sigma_{l}, \sigma_{h}\right\}$, where $l$ denotes the low regime and $h$ the high regime. I denote the transition probabilities of the Markov chains as 


$$
P\left(\mu_{t}=\mu_{h} \mid \mu_{t-1}=\mu_{h}\right)=p_{h h}^{\mu}, P\left(\mu_{t}=\mu_{l} \mid \mu_{t-1}=\mu_{l}\right)=p_{l l}^{\mu}
$$

and $P\left(\sigma_{t}=\sigma_{h} \mid \sigma_{t-1}=\sigma_{h}\right)=p_{h h}^{\sigma}, P\left(\sigma_{t}=\sigma_{l} \mid \sigma_{t-1}=\sigma_{l}\right)=p_{l l}^{\sigma}$

where the probabilities of transitioning between regimes are denoted $p_{h l}^{\mu}=1-p_{l l}^{\mu}$ and $p_{l h}^{\mu}=1-p_{h h}^{\mu}$ for the mean regime, and $p_{h l}^{\sigma}=1-p_{l l}^{\sigma}$ and $p_{l h}^{\sigma}=1-p_{h h}^{\sigma}$ for the volatility regime.

Since the state variables, $S_{t}$ and $V_{t}$ are latent, information about the unobserved regime must be inferred from observations on the data. Such inference is provided by estimating the filtered or smoothed probability of being in state of $S_{t}$ and $V_{t}$ conditional on estimated of the model parameters and the data. Specifically, the posterior proba-

bility is computed as $P\left[S_{t}=j \mid Y_{s}, \widehat{\Theta}\right]$ and $P\left[V_{t}=j \mid Y_{s}, \widehat{\Theta}\right]$, where $\widehat{\Theta}$ is the maximum likelihood estimate of parameters in the model and $Y_{s}$ denotes observations available through time s. The filtered probability is computed by using observations up to time $\mathrm{t}$ $\left(Y_{t}\right)$, and the smoothed probability is calculated with the whole sample data $\left(Y_{T}\right)$. All the parameters are estimated using maximum likelihood constructed with with filtered probabilities of $S_{t}$ and $V_{t}$. Recently Bai and Wang (2011) articulate that the proposed model with two mean states and two variance states can be viewed as a restricted version of the Hamilton (1989) model with four states. They explain detailed estimation algorithms and show that this restricted model provides good estimates for the recession probabilities with quarterly data. This paper also confirms the empirical fact with monthly industrial production growth data.

\subsection{Asset Pricing Tests on the Size Premium}

The Fama and French (1993) three-factor model is given as

$$
E\left(R_{i}\right)=\gamma_{0}+\beta_{i, M}\left(R_{m t}-R_{f t}\right)+\beta_{i, s} R_{s m b, t}+\beta_{i, h} R_{h m l, t}
$$


where $E\left(R_{i}\right)$ is the return of asset $i$,and $\gamma_{0}$ is the zero beta rate. $R_{m t}-R_{f t}$ is the market portfolio excess return, $R_{s m b, t}$ is the return to the SMB, and $R_{h m l, t}$ is the return on the HML.

While it has been argued that the size effect has disappeared, the right test to conduct is whether we can drop the SMB from the pricing factors. Namely, if the size effect is not a systematic risk, the SMB can be dropped from the Fama-French three-factor model. Intuitively, if the other factors are enough to price the SMB, those factors will price any assets that the SMB prices. The proper test to drop the SMB from the Fama-French three-three factor model can be stated with the following time-series equation. ${ }^{1}$

\section{Hypothesis 0: the SMB is redundant.}

$$
R_{s m b, t}=\alpha+\beta_{s m b}\left(R_{m t}-R_{f t}\right)+h_{s m b}\left(R_{h m l, t}\right)+\varepsilon_{s m b, t}
$$

If $\alpha=0$, the size premium is explained by the other two Fama-French factors and the SMB factor can be dropped from the Fama-French three-factor model.

\subsection{Asset Pricing Tests with Regime Switching Models}

I propose four testable hypotheses to determine if the size premium is redundant in the high volatility regime or in a recession regime.

\section{Hypothesis I: the SMB is redundant during the high volatility regimes.}

To test if the hypothesis I holds, I combine (2.1) and (2.2) to estimate the following

\footnotetext{
${ }^{1}$ Many practitioners mistakenly think that the SMB can be dropped if the average SMB is equal to zero. (or the factor is priced). However, this is not the proper test unless the factor is orthogonalized.
} 
bivariate regime switching model (Model 1).

$$
\begin{aligned}
& R_{s m b, t}=\alpha+\phi I\left(V_{t}=H\right)+\beta_{s m b}\left(R_{m t}-R_{f t}\right)+h_{s m b}\left(R_{h m l, t}\right)+\varepsilon_{s m b, t} \\
& \Delta y_{t}=\mu\left(S_{t}\right)+\varepsilon_{t}, \varepsilon_{t} \sim N\left(0, \sigma^{2}\left(V_{t}\right)\right), \varepsilon_{s m b, t} \sim N\left(0, \sigma^{2}\right)
\end{aligned}
$$

where $R_{s m b, t}$ is the return to the SMB, $R_{m t}-R_{f t}$ is the market portfolio excess return, $R_{h m l, t}$ is the return on the HML, $\Delta y_{t}$ is the monthly growth rate of the industrial production. $I\left(V_{t}=H\right)$ is the indicator function having the value 1 for high-vol regimes and the value 0 for other regimes. $S_{t}$ and $V_{t}$ are independent latent state variables for the regimes of mean and variance. As in the univariate regime switching model for the industrial production growth, I assume that the probability of changing mean regimes is independent of the probability of changing volatility regimes. If $\phi=0$, the size premium is redundant during the high volatility regime.

\section{Hypothesis II: the SMB is redundant during the recession regimes.}

To test if the hypothesis II holds, I estimate the following bivariate regime switching model (Model 2).

$$
\begin{aligned}
& R_{s m b, t}=\alpha+\lambda I\left(S_{t}=L\right)+\beta_{s m b}\left(R_{m t}-R_{f t}\right)+h_{s m b}\left(R_{h m l, t}\right)+\varepsilon_{s m b, t} \\
& \Delta y_{t}=\mu\left(S_{t}\right)+\varepsilon_{t}, \varepsilon_{t} \sim N\left(0, \sigma^{2}\left(V_{t}\right)\right), \varepsilon_{s m b, t} \sim N\left(0, \sigma^{2}\right)
\end{aligned}
$$

where $I\left(S_{t}=L\right)$ is the indicator function having the value 1 for low-mean (recession) regimes and the value 0 for other regimes. As before, I assume that the probability of changing mean regimes is independent of the probability of changing volatility regimes. If $\lambda=0$, the size premium is redundant during the recession regime.

Models 1 and 2 may be too restrictive because factor loadings in this regression can be also regime-dependent. As robustness checks, I test the same hypotheses with the bivariate model with regime switching betas. The betas of the RMRF and HML are 
changing across different volatility regimes in the model 3 and across different business cycle regimes in the model 4 , respectively.

Hypothesis III: the SMB is redundant during the high volatility regimes with regime switching volatility betas (Model 3).

$$
\begin{aligned}
& R_{s m b, t}=\alpha+\phi I\left(V_{t}=H\right)+\left(\beta_{s m b}+\beta_{s m b} I\left(V_{t}=H\right)\right)\left(R_{m t}-R_{f t}\right)+\left(h_{s m b}+h_{s m b} I\left(V_{t}=H\right)\right)\left(R_{h m l, t}\right)+\varepsilon_{s m b, t} \\
& \Delta y_{t}=\mu\left(S_{t}\right)+\varepsilon_{t}, \varepsilon_{t} \sim N\left(0, \sigma^{2}\left(V_{t}\right)\right), \varepsilon_{s m b, t} \sim N\left(0, \sigma^{2}\right)
\end{aligned}
$$

Hypothesis IV: the SMB is redundant during the recession regimes with regime switching recession betas (Model 4).

$$
\begin{aligned}
& R_{s m b, t}=\alpha+\lambda I\left(S_{t}=L\right)+\left(\beta_{s m b}+\beta_{s m b} I\left(S_{t}=L\right)\right)\left(R_{m t}-R_{f t}\right)+\left(h_{s m b}+h_{s m b} I\left(S_{t}=L\right)\right)\left(R_{h m l, t}\right)+\varepsilon_{s m b, t} \\
& \Delta y_{t}=\mu\left(S_{t}\right)+\varepsilon_{t}, \varepsilon_{t} \sim N\left(0, \sigma^{2}\left(V_{t}\right)\right), \varepsilon_{s m b, t} \sim N\left(0, \sigma^{2}\right)
\end{aligned}
$$

\section{Data}

The data are from July 1926 to November 2011 (1,025 monthly observations). The monthly market excess returns (RMRF), the value premium (HML), and the size premium (SMB) are downloaded from Kenneth French's website. ${ }^{2}$ The index of industry production is from the Federal Reserve Bank of St. Louis. In order to conduct the robustness checks, I also report the estimation results using the subsample from July 1963 to November 2011. The starting date is selected to be consistent with the sample used in Fama and French (1992).

Table 1 reports summary statistics on the Fama-French three factors and the in-

\footnotetext{
${ }^{2}$ I thank Kenneth French for making his data available on line (http ://mba.tuck.dartmouth.edu/pages/faculty/ken.french/data_library.html).
} 
dustrial production growth. Panel A reports for the whole sample and Panel B for the subsample, respectively. In the whole sample, the mean excess return on the U.S. stock market portfolio is about $0.62 \%$ per month and is highly volatile ( $5.46 \%$ per month). The SMB and the HML have lower mean returns, $0.24 \%$ and $0.3 \%$ per month with similar lower volatility ( $3.32 \%$ for the SMB and $3.57 \%$ for the HML, respectively). The industrial production growth is on average $3.14 \%$ and its volatility is $21.94 \%$ in annual-

ized terms. In the subsample, one notable fact is the reduction of the volatility in the industrial production growth from $21.91 \%$ to $9.12 \%$. Figure 1 also confirms that there were apparent reduction in the volatility of U.S. output fluctuations in the early 1980's.

\section{Empirical Results}

\subsection{Preliminary Results}

\subsubsection{Univariate Regime Switching Model}

I first estimate a univariate regime switching model $((2.1))$ for the industrial production growth $\left(\Delta y_{t}\right)$.

Table 2 presents the estimation results in panel A for the whole sample and panel B for the subsample. The regime represented by $\mu\left(S_{t}\right)=\mu_{h}$ has average growth equal to annualized $5.3 \%$ for the whole sample and $4.57 \%$ for the subsample while the regime represented by $\mu\left(S_{t}\right)=\mu_{l}$, has an average growth rate of $-9.94 \%$ for the whole sample and $-5.35 \%$ for the subsample. Thus, the high growth regime $\left(S_{t}=h\right)$ is an expansion state and the low growth regime $\left(S_{t}=l\right)$ a recession state. These fluctuations in the regime switching mean growth rate of the industrial production capture business cycles in the economy.

The volatility estimates provide the degree to which macroeconomic risk varies across 
regimes. The high volatility regime $\left(\sigma\left(V_{t}\right)=\sigma_{h}\right)$ has residual variance of 40.27 for the whole sample and 15.51 for the subsample, whereas the low volatility regime $\left(\sigma\left(V_{t}\right)=\sigma_{l}\right)$ has the much smaller variance 7.56 for the whole sample and 5.47 for the subsample.

The probability that high mean growth will be followed by another high mean growth regime is 0.97 for the whole sample and 0.98 for the subsample, implying that the high mean regime is expected to last on average about 33 months. The high volatility regimes are less persistent than the mean regimes. For example, the probability that a high volatility regime will be followed by another high volatility regime is 0.93 for the whole sample but 0.72 for the subsample. This feature is consistent with the reduction of output volatility since 1980s. While it is often said that recessions coincides with the high volatility regimes, I find that the correlation of two are quite small (0.2) since July 1963. Perhaps the recession would be officially near the end (or ended), whereas the economic uncertainty could be still high.

Figure 2 and 3 show time-series plots of the smoothed posterior probabilities of being in a high volatility regime $\left(\sigma\left(V_{t}\right)=\sigma_{h}\right)$ and the posterior probabilities of being in a low mean regime $\left(\mu\left(S_{t}\right)=\mu_{l}\right)$. The estimated mean regimes are closely tracking business cycle patterns because they coincide almost exactly with recession periods announced by the NBER. The volatility regimes pick up the so-called great moderation since 1984 . Figure 2 shows that from 1984 to the recent period before 2008 financial crisis, the probabilities of being in a high volatility regimes are essentially zero. Figure 3 using subsample data shows less extreme results with high volatility regimes around 1999 and 2006.

\subsubsection{Simple Asset Pricing Tests}

I estimate the Fama-French model(2.2) and test if $\alpha=0$.

Table 3 presents that the SMB alpha $(\alpha)$ with Newey-West standard errors. The 
alpha is only $0.11 \%$ with t-statistics 1.14 for the full sample and $0.24 \%$ with t-statistics 1.72 for the subsample. The results show that the size effect does not exist unconditionally in the data, and the SMB factor can be dropped from the Fama-French model unconditionally.

\subsection{Asset Pricing Tests with Macroeconomic Uncertainty}

I propose four testable hypotheses to determine if the size premium is redundant in the high volatility regime or in a recession regime.

\section{Hypothesis I: the SMB is redundant during the high volatility regimes.}

I reproduce the model (Model 1) to test the hypothesis I for an easier explanation.

$$
\begin{aligned}
& R_{s m b, t}=\alpha+\phi I\left(V_{t}=H\right)+\beta_{s m b}\left(R_{m t}-R_{f t}\right)+h_{s m b}\left(R_{h m l, t}\right)+\varepsilon_{s m b, t} \\
& \Delta y_{t}=\mu\left(S_{t}\right)+\varepsilon_{t}, \varepsilon_{t} \sim N\left(0, \sigma^{2}\left(V_{t}\right)\right), \varepsilon_{s m b, t} \sim N\left(0, \sigma^{2}\right)
\end{aligned}
$$

where $R_{s m b, t}$ is the return to the SMB, $R_{m t}-R_{f t}$ is the market portfolio excess return, $R_{h m l, t}$ is the return on the HML, $\Delta y_{t}$ is the monthly growth rate of the industrial production. $I\left(V_{t}=H\right)$ is the indicator function having the value 1 for high-vol regimes and the value 0 for other regimes. $S_{t}$ and $V_{t}$ are latent state variables for the regimes of mean and variance.

Table 4 presents that $\phi$ is 0.64 with t-statistics 2.78 for the whole sample and 1.11 with t-statistics 2.21 for the subsample. The results clearly indicate that the SMB is not redundant in a high volatility regime. Other parameter estimates are pretty close to those from univariate models in Tables 2 and 3. Figures 4 and 5 show time-series plots of the smoothed posterior probabilities of being in a high volatility regime $\left(\sigma\left(V_{t}\right)=\sigma_{h}\right)$ and the posterior probabilities of being in a low mean regime $\left(\mu\left(S_{t}\right)=\mu_{l}\right)$ for the models $1,2,3$, and 4 for the whole sample. Figures 6 and 7 show the same time-series plots 
for the subsample. For the model 1, the estimated mean regimes are closely tracking business cycle patterns announced by the NBER. The volatility regimes pick up the so-called great moderation since 1984. Identified regimes are pretty close to those from a univariate regime switching model of the industrial production growth.

\section{Hypothesis II: the SMB is redundant during the recession regimes.}

I reproduce the model (Model 2) to test the hypothesis II for an easier explanation.

$$
\begin{aligned}
& R_{s m b, t}=\alpha+\lambda I\left(S_{t}=L\right)+\beta_{s m b}\left(R_{m t}-R_{f t}\right)+h_{s m b}\left(R_{h m l, t}\right)+\varepsilon_{s m b, t} \\
& \Delta y_{t}=\mu\left(S_{t}\right)+\varepsilon_{t}, \varepsilon_{t} \sim N\left(0, \sigma^{2}\left(V_{t}\right)\right), \varepsilon_{s m b, t} \sim N\left(0, \sigma^{2}\right)
\end{aligned}
$$

where $I\left(S_{t}=L\right)$ is the indicator function having the value 1 for low-mean (recession) regimes and the value 0 for other regimes. If $\lambda=0$, the size premium is redundant during the recession regime.

Table 5 indicates that $\lambda$ is 0.15 with t-statistics 0.14 for the whole sample and 0.66 with t-statistics 1.70 for the subsample. The results indicate that the SMB is redundant in a recession regime. Other parameter estimates are largely similar to those in Table 4. The estimated mean and the volatility regimes in Figures 4,5,6, and 7 are also close to the regimes identified in the model 1.

Models 1 and 2 are too restrictive because factor loadings can be also regimedependent. The estimated SMB alphas could reflect the omission of regime-dependent factor loadings. To check the robustness of the results, I also test the hypothesis I and II with the regime switching betas. The betas of the RMRF and HML are changing across different volatility regimes in the model 3 and different business cycle regimes in the model 4, respectively. I reproduce the estimated equation for the SMB factor for an easier explanation.

\section{Hypothesis III: the SMB is redundant during the high volatility regimes}


with regime switching volatility betas (Model 3).

$R_{s m b, t}=\alpha+\phi I\left(V_{t}=H\right)+\left(\beta_{s m b}+\beta_{s m b} I\left(V_{t}=H\right)\right)\left(R_{m t}-R_{f t}\right)+\left(h_{s m b}+h_{s m b} I\left(V_{t}=H\right)\right)\left(R_{h m l, t}\right)+\varepsilon_{s m b, t}$

Table 6 shows that the HML betas are regime-dependent while the market betas are regime-invariant. In a high volatility regime, the HML loadings are 0.59 with t-statistics 10 for the whole sample and 0.86 with t-statistics 8.23 for the subsample. And $\phi$ becomes smaller in this specification. $\phi$ is 0.55 with t-statistics 2.44 for the whole sample and 0.75 with t-statistics 1.95 for the subsample. Thus, the high SMB alpha in the high volatility regimes are partly explained by the increase in the HML loadings, indicating that the SMB is not redundant in a high volatility regime. The estimated mean and the volatility regimes in Figures 4,5,6, and 7 are again close to the regimes identified in the model 1.

Hypothesis IV: the SMB is redundant during the recession regimes with regime switching recession betas (Model 4).

$R_{s m b, t}=\alpha+\lambda I\left(S_{t}=L\right)+\left(\beta_{s m b}+\beta_{s m b} I\left(S_{t}=L\right)\right)\left(R_{m t}-R_{f t}\right)+\left(h_{s m b}+h_{s m b} I\left(S_{t}=L\right)\right)\left(R_{h m l, t}\right)+\varepsilon_{s m b, t}$

Table 7 presents that the HML betas are regime-dependent. In a recession regime, the HML loadings are 0.72 with t-statistics 9.14 for the whole sample and 0.49 with t-statistics 4.66 for the subsample. Thus, the high SMB in the recession regimes are partly explained by the increase in the HML loadings. And $\lambda$ is 0.39 with t-statistics 1.09 for the whole sample and 0.05 with t-statistics 0.42 for the subsample. Particularly for the subsample, the SMB alpha has only 0.42 t-statistics with regime-dependent HML loadings while it has 1.70 t-statistics in the model 2. The results strengthen the hypothesis that the SMB is redundant in a recession regime. The estimated volatility regimes in Figures 4 and 6 are close to the regimes identified in the model 1 while the 
estimated mean regimes seem to have more noises.

\subsection{Economic Interpretation}

The empirical results presented in the previous section indicate that the SMB factor earns a significant independent risk premium only in uncertain macroeconomic states, even though it has a zero risk premium on average.

Perez-Quiros and Timmermann (2000), based on the imperfect capital market theories, claim that small firms' collateral is likely to be very low during the recession, and with little collateral they do not have the same access to credit markets that are enjoyed by large firms. Investors would ask a compensation for small firms if those firms' risk should be disproportionately affected by tighter credit conditions. Thus, the high returns to small firms might be compensation for taking this credit-related risk in a recession regime.

The main reason to observe the capital market imperfections is the information asymmetry between borrowers and lenders (e.g. adverse selection and moral hazard problems). When the asymmetric information problems becomes severe between lenders and borrowers, the higher credit risk will be reflected as a higher external finance premia, a wedge between the external financing by issuing equity or debt and the internal financing by retaining earnings. There are many empirical results supporting the impact of capital market imperfections on firms' financing decisions across different economic environments. For example, Choe, Masulis, and Nanda (1993) present that firms' financing decisions are affected by business cycles. Ozkan and Ozkan (2004) find that small, non-rated firms with strong investment opportunities and volatile cash flow, i.e., with a high degree of information asymmetry, hold more cash as a safeguard against the worsening credit conditions. 
In well-developed financial markets such as U.S.A., perhaps recession itself would not hamper raising capitals for the small firms unless it coincides with the high uncertainty. I argue that even in the recession if it is not companied with severe economic uncertainty, the capital market could function normally. Only high macroeconomic volatility regime would discourage the provision of credit by increasing uncertainty about prospective returns and exposing banks to potentially large losses.

Baum, Caglayan, and Ozkan (2009) report the potentially adverse effects of macroeconomic volatility on the allocation of banks' lending behavior. Based on a clear negative association between proxies of macroeconomic uncertainty and the cross-sectional variability of banks' loan-to-asset ratios, they argue that banks will behave more homogenously during the times of higher macroeconomic uncertainty. This adverse effects would affect small firms significantly. Gertler and Gilchrist (1994) suggest that small firms are more dependent on bank loans while large firms have better access to direct sources of credit such as commercial paper.

Investors would ask compensation for this systematic risk to credit-constrained smallsize firms in high volatility regime. Indeed the results in this paper support the implications. I find that the size premium is not redundant only in a high volatility regime from time-series asset pricing tests based on the Fama-French three-factor model.

\section{Conclusion}

Since Banz (1981) first reports that small-capitalization firms on the New York Stock Exchange (NYSE) earned higher average returns than is predicted by the CAPM from 1936 to 1975 , the size effect has been subject to many theoretical and empirical scrutinies. van Dijk (2011) identifies two contradictory developments in research on the size effect since the late 1990s. Many theoretical models are developed to explain the size effect 
(e.g. Berk, Green, and Naik (1999)), but the size effect has disappeared since the early 1980s (e.g.Horowitz, Loughran, and Savin (2000)).

If the anomalies are a result of data snooping bias, these are expected to disappear in the data soon after they have been reported. If the size premium has indeed disappeared, the SMB should not be interpreted as a systematic risk factor to generate a risk premium in the rational asset pricing model. It would be puzzling why Fama and French still keep their SMB factor in explaining the cross-section of stock returns.

In this paper, I document a new stylized fact on the size effect to resolve this issue. I find that the size factor (SMB) earns a significant independent risk premium only in uncertain macroeconomic states, even though it has a zero risk premium on average. This result is robust across different time periods and model specifications. I claim that the so-called "Great Moderation" coined by Ben Bernanke has been effectively masked the size effect until recently. Kim and Nelson (1999) and McConnell and PerezQuiros (2000) show that US output volatility had declined substantially in the early 1980s. Interestingly, this period coincides with the initial publication of the size effect. However, the size effect has been resurrected since the recent financial crisis coupled with uncertain economic environment.

The imperfect capital market theories indicate that small firms' collateral is likely to be very low during the recession, and with little collateral they do not have the same access to credit markets that are enjoyed by large firms. Investors would ask a compensation for small firms if those firms' risk should be disproportionately affected by tighter credit conditions. Thus, the high returns to small firms might be compensation for taking this credit-related risk in a recession regime.

However, in well-developed financial markets such as U.S.A., perhaps recession itself would not hamper raising capitals for the small firms unless it coincides with the high uncertainty. Only high macroeconomic volatility regime would discourage the provision 
of credit by increasing uncertainty about prospective returns and exposing banks to potentially large losses. Gertler and Gilchrist (1994) suggest that small firms are more dependent on bank loans, and Baum, Caglayan, and Ozkan (2009) present evidence that the adverse effects of macroeconomic volatility on the allocation of banks' lending behavior. Perhaps, the macroeconomic volatility will do more harm to small-sized firms in this respect. Investors would ask compensation for this systematic risk to creditconstrained small-size firms in high volatility regime. Indeed the results in this paper support the implications. I find that the size premium is not redundant only in a high volatility regime but redundant in other regimes from time-series asset pricing tests based on the Fama-French three-factor model. 


\section{References}

Bai, J., and P. Wang, 2011, "Conditional Markov chain and its application in economic time series analysis," Journal of Applied Econometrics, 26, 715-734.

Banz, R. W., 1981, "The Relationship Between Return and Market Value of Common Stocks," Journal of Financial Economics, 9, 3-18.

Baum, C. F., M. Caglayan, and N. Ozkan, 2009, "The Second Moments Matter: The Impact of Macroeconomic Uncertainty on the Allocation of Loanable Funds," Economic Letters, $102,87-89$.

Berk, J. B., R. C. Green, and V. Naik, 1999, "Optimal Investment, Growth Options, and Security Returns," Journal of Finance, 54, 1553-1607.

Choe, H., R. W. Masulis, and V. K. Nanda, 1993, "Common Stock Offerings Across the Business Cycle: Theory and Evidence," Journal of Empirical Finance, 1, 3-31.

Fama, E., and K. French, 1992, "The Cross-Section of Expected Stock Returns," Journal of Finance, 47, 427-465.

— , 1993, "Common Risk Factors in the Returns on Stocks and Bonds," Journal of Financial Economics, 33, 3-56.

Gertler, M., and S. Gilchrist, 1994, "Monetary policy, business cycles, and the behavior of small manufacturing firms," Quarterly Journal of Economics, 109, 309-340.

Hamilton, J. D., 1989, "A New Approach to the Economic Analysis of Nonstationary Time Series and the Business Cycle," Econometrica, 57, 357-384.

Horowitz, J. L., T. Loughran, and N. E. Savin, 2000, "Three Analyses of the Firm Size Premium," Journal of Empirical Finance, 7, 143-153.

Hou, K., and M. A. van Dijk, 2010, "Profitability shocks and the size effect in the cross-section of expected stock returns," SSRN Working Paper Series. 
Kim, C., and C. Nelson, 1999, "Has the U.S. Economy Become More Stable? A Bayesian Approach Based on a Markov-Switching Model of the Business Cycle," Review of Economics and Statistics, 81, 1-10.

Lettau, M., S. C. Ludvigson, and J. A. Wachter, 2008, "The Declining Equity Premium: What Role Does Macroeconomic Risk Play?," Review of Financial Studies, 21, 1653-1687.

McConnell, M. M., and G. Perez-Quiros, 2000, "Output Fluctuations in the United States: What Has Changed since the Early 1980's?," American Economic Review, 90(5), 1464-1476.

Ozkan, A., and N. Ozkan, 2004, "Corporate cash holdings: An empirical investigation of UK companies," Journal of Banking and Finance, 28, 2103-2134.

Perez-Quiros, G., and A. Timmermann, 2000, "Firm Size and Cyclical Variations in Stock Returns," Journal of Finance, 55, 1229-1262.

Schwert, G. W., 2003, "Anomalies and Market Efficiency," Handbook of Economics of Finance. van Dijk, M. A., 2011, "Is Size Dead? A Review of the Size Effect in Equity Returns," Journal of Banking and Finance, 35, 3263-3274. 
The Industrial Production Growth

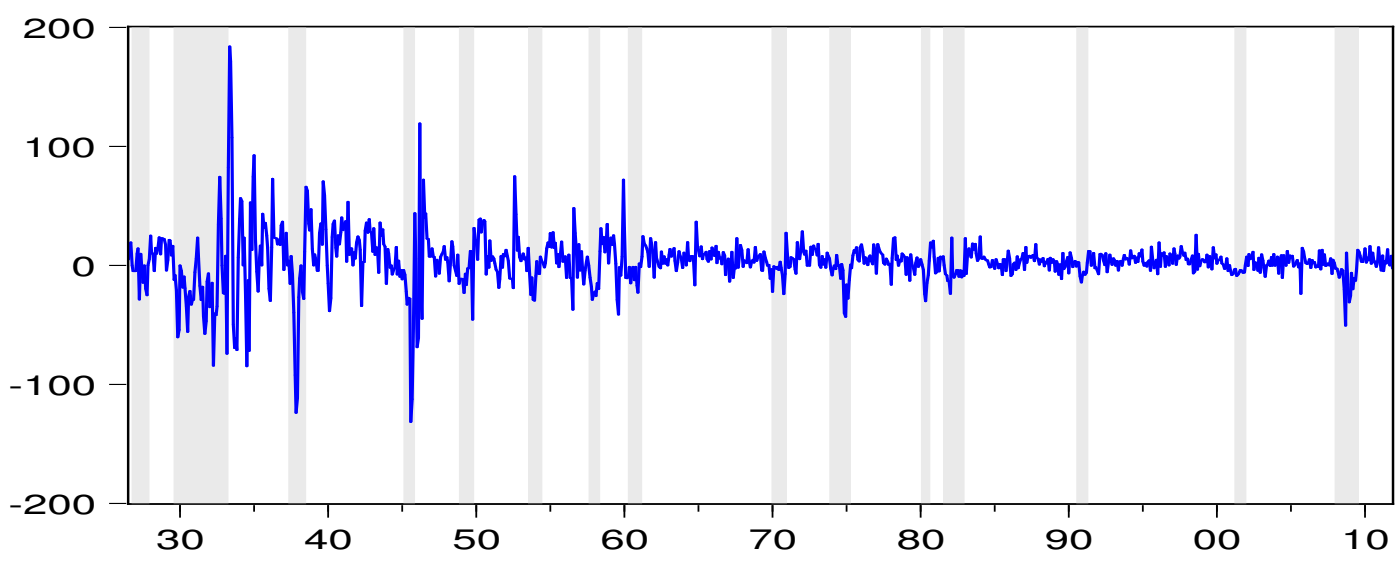

the SMB

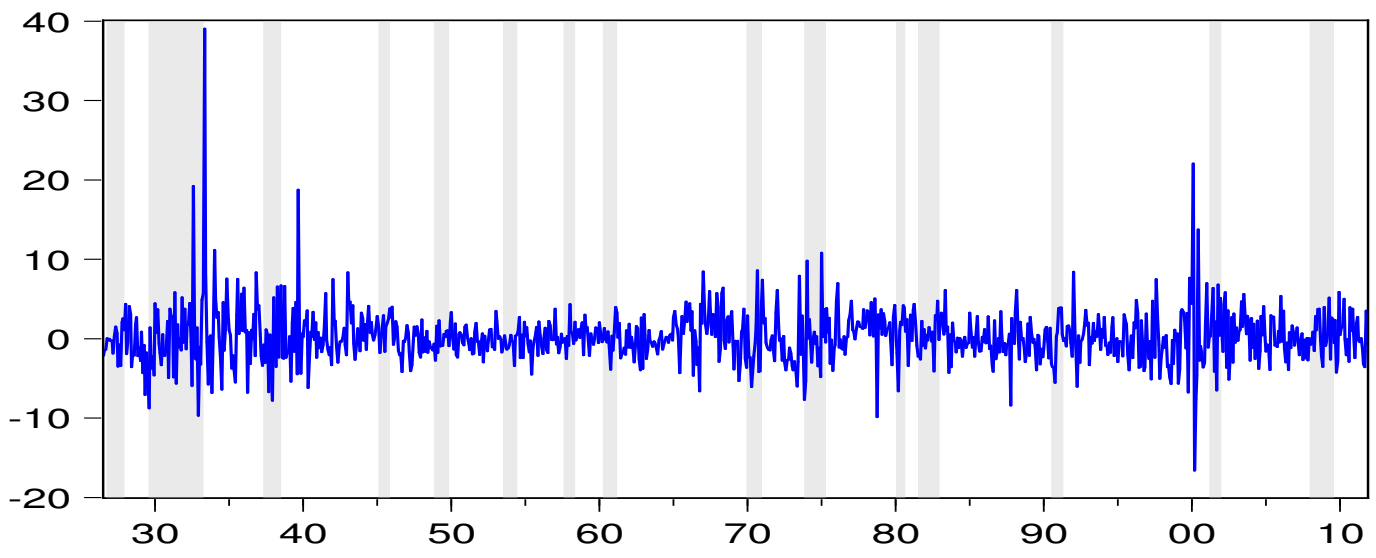

This figure shows the growth rates of industrial production. The shaded lines in the plot correspond to NBER recession dates. The data are monthly and span the period from 1926:07 to 2011:11.

Figure 1: The Growth rates of Industrial Production 
Prob (High Volatility)

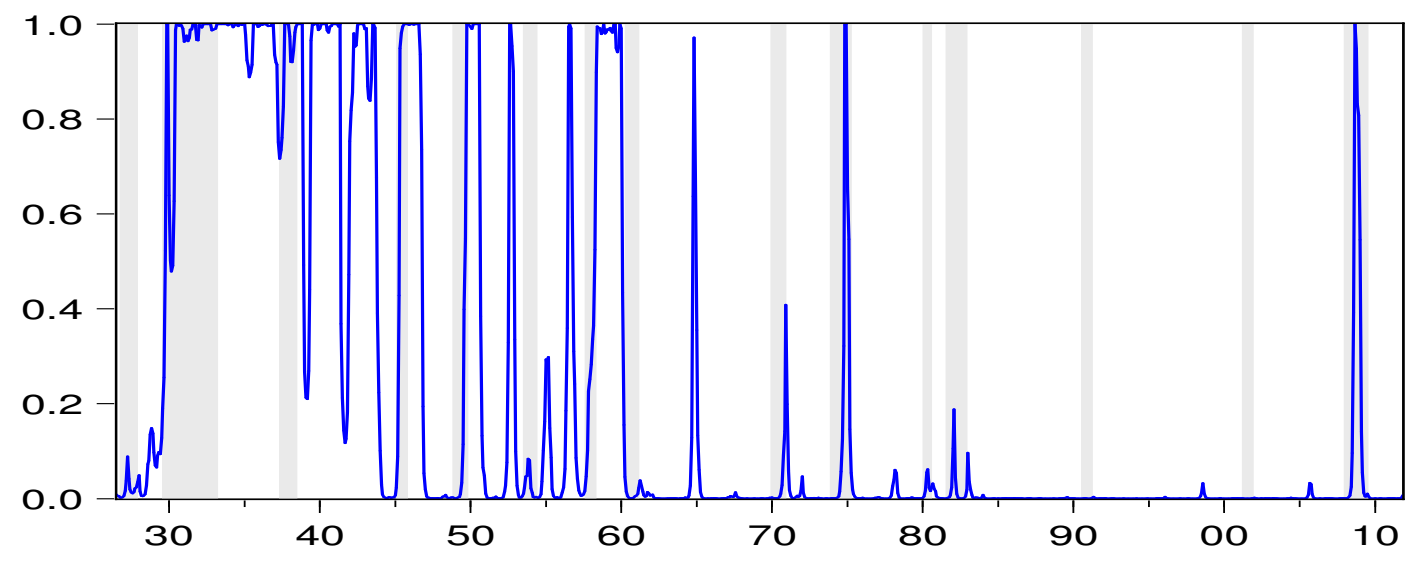

Prob (Recession)

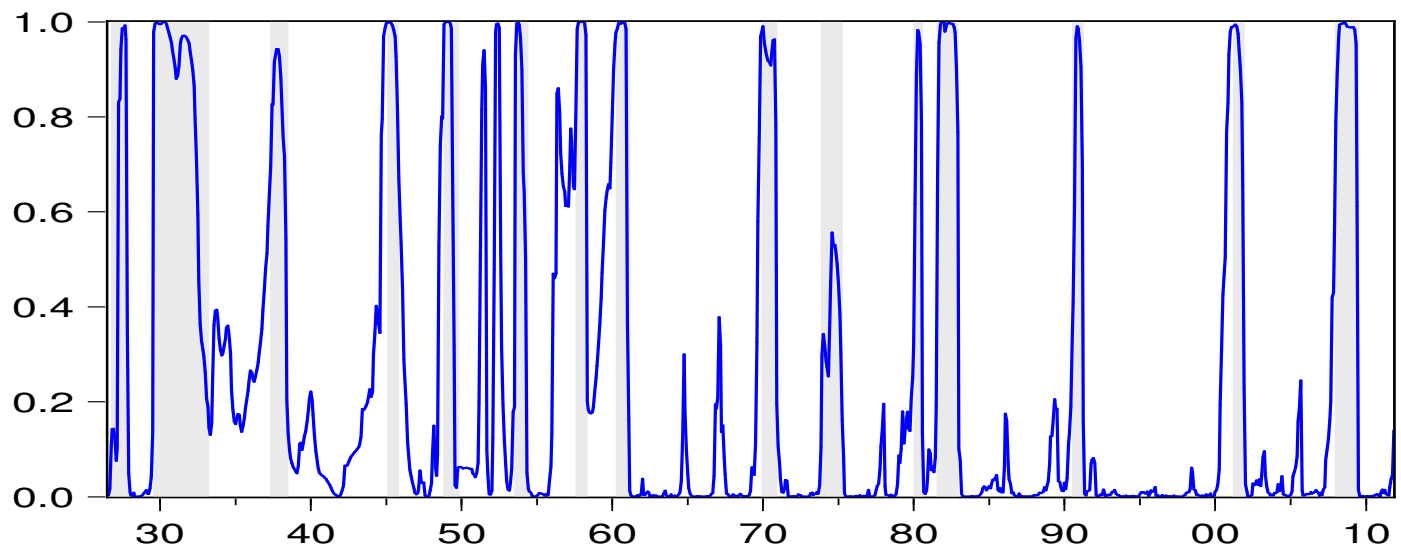

This figure plots the time-series of smoothed state probabilities. Prob (High Volatility) is the unconditional probability of being in a high volatility regime, calculated by summing the probability of being in a high volatility regime and high mean regime, and the probability of being in a high volatility regime and low mean regime. Prob (Recession mean) is calculated analogously. The shaded lines in the plot correspond to NBER recession dates. The data are monthly and span the period from 1926:07 to 2011:11.

Figure 2: Smoothed State Probabilities (1926:07 - 2011:11) 
Prob (High Volatility)
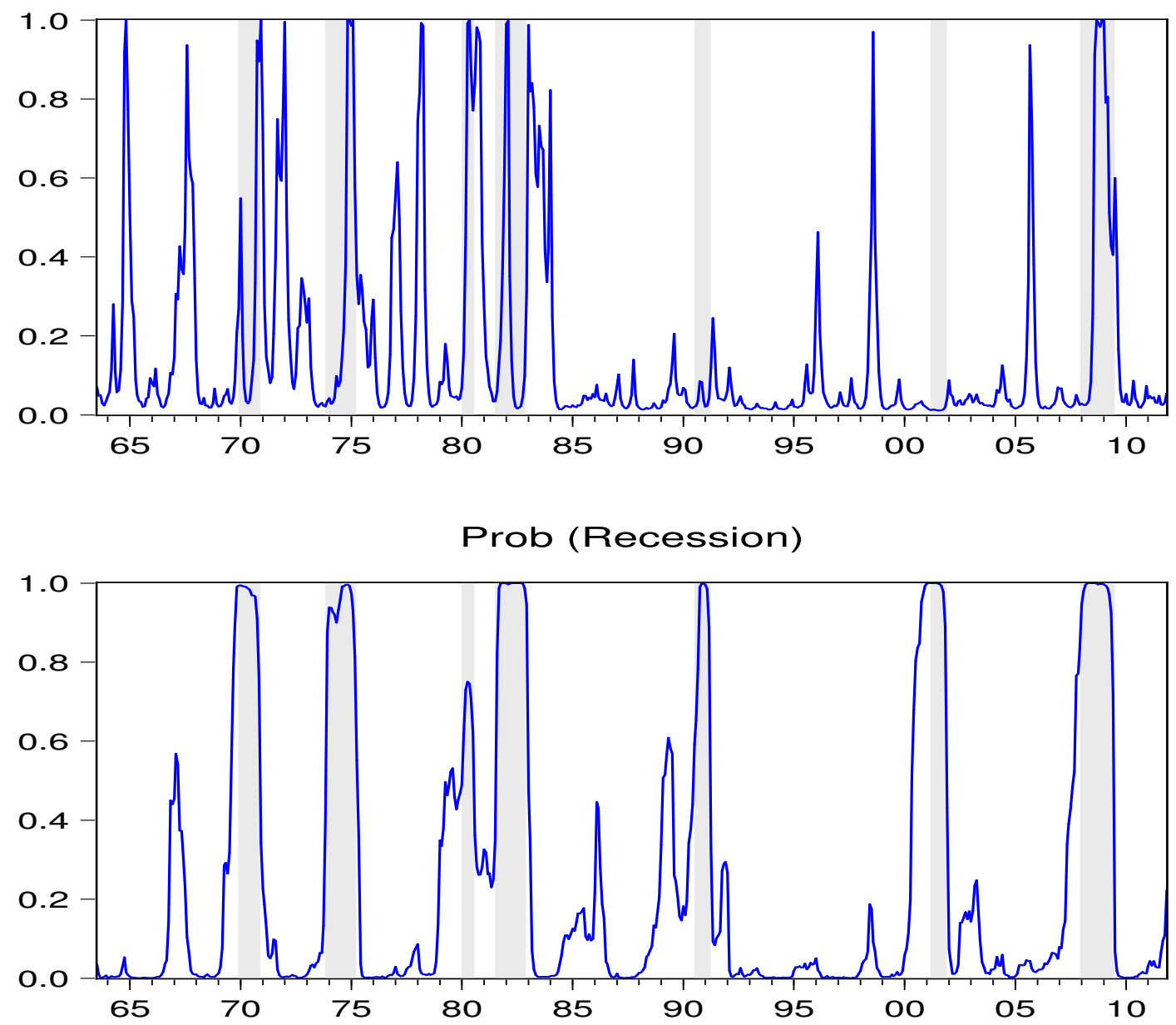

This figure plots the time-series of smoothed state probabilities. Prob (High Volatility) is the unconditional probability of being in a high volatility regime, calculated by summing the probability of being in a high volatility regime and high mean regime, and the probability of being in a high volatility regime and low mean regime. Prob (Recession mean) is calculated analogously. The shaded lines in the plot correspond to NBER recession dates. The data are monthly and span the period from 1963:07 to 2011:11.

Figure 3: Smoothed State Probabilities (1963:07 - 2011:11) 
Prob (High Volatility,Model1)

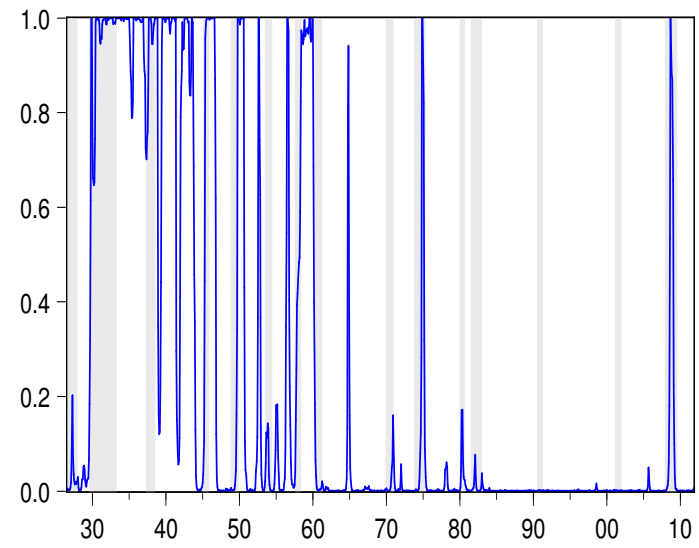

Prob (High Volatility,Model3)

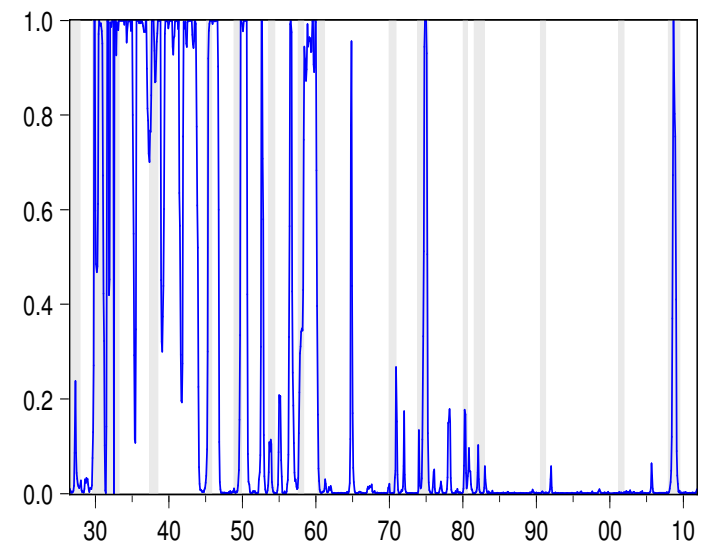

Prob (High Volatility,Model2)

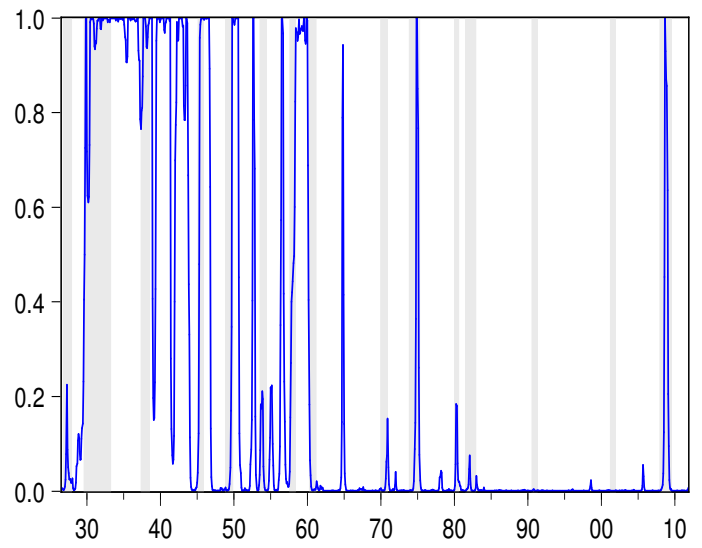

Prob (High Volatility,Model4)

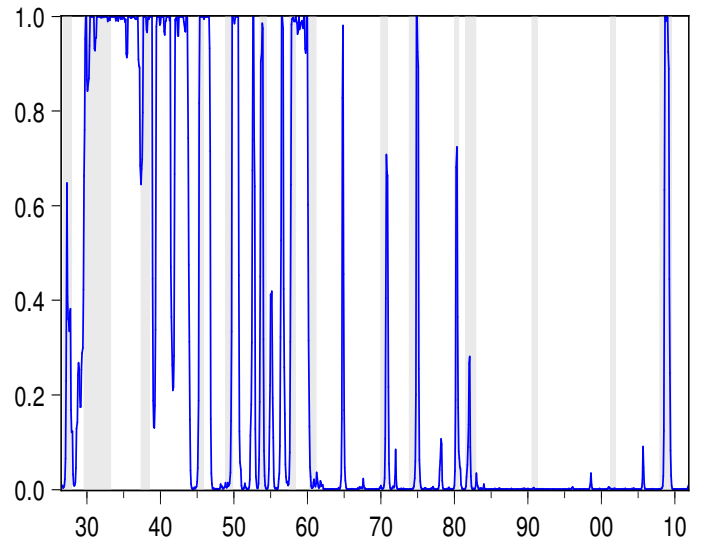

This figure plots the time-series of smoothed probabilities of high volatility regimes from four models defined in the section 2. Prob (High Volatility) is the unconditional probability of being in a high volatility regime, calculated by summing the probability of being in a high volatility regime and high mean regime, and the probability of being in a high volatility regime and low mean regime. The shaded lines in the plot correspond to NBER recession dates. The data are monthly and span the period from 1926:07 to 2011:11.

Figure 4: Smoothed Probabilities of High Volatility regimes (1926:07 - 2011:11) 
Prob (Recession,Model1)

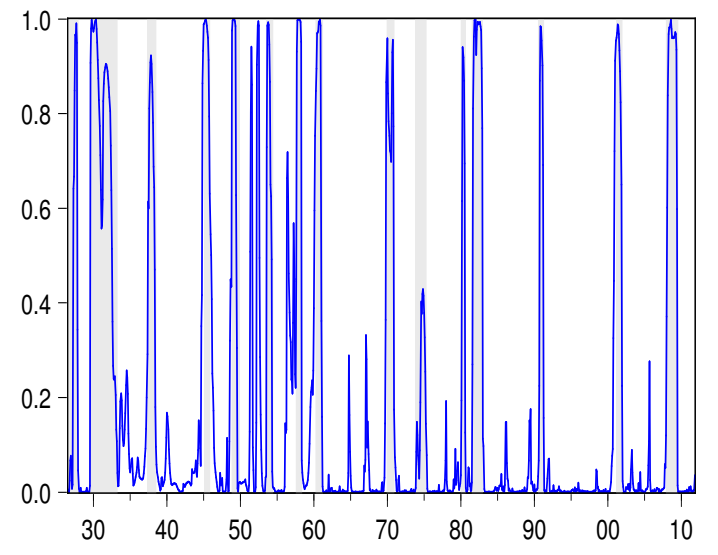

Prob (Recession,Model3)

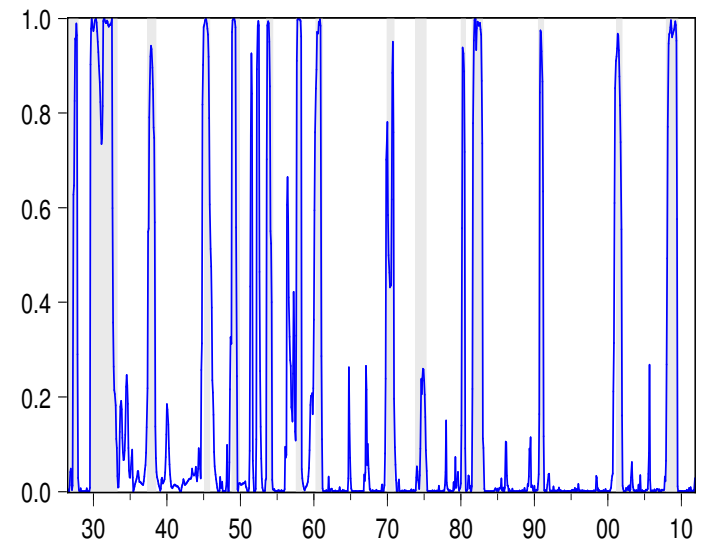

Prob (Recession,Model2)

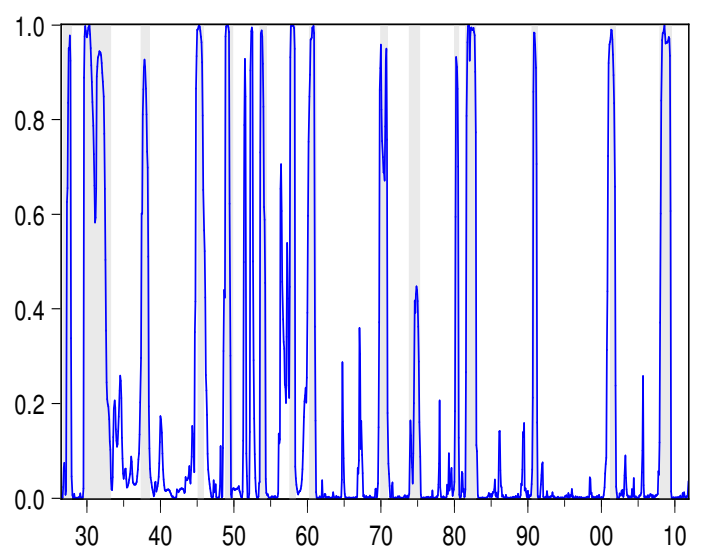

Prob (Recession,Model4)

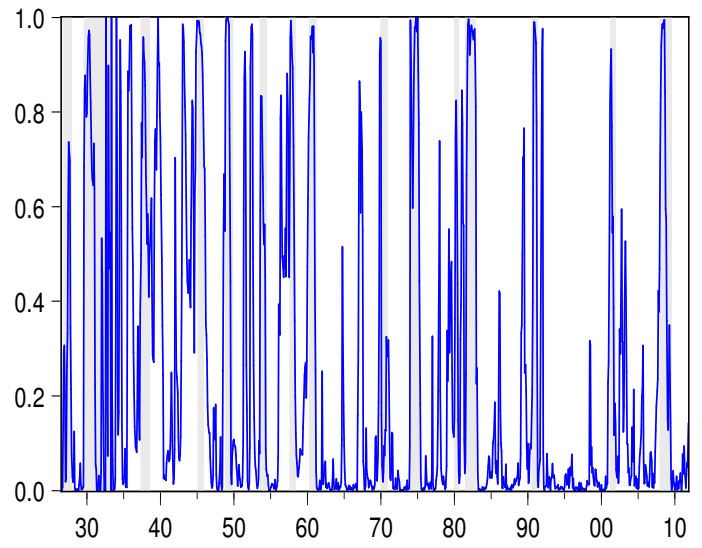

This figure plots the time-series of smoothed probabilities of recession regimes from four models defined in the section 2. Prob (Recession) is the unconditional probability of being in a low mean regime, calculated by summing the probability of being in a high volatility regime and low mean regime, and the probability of being in a low volatility regime and low mean regime. The shaded lines in the plot correspond to NBER recession dates. The data are monthly and span the period from 1926:07 to 2011:11.

Figure 5: Smoothed Probabilities of Recession regimes (1926:07 - 2011:11) 
Prob (High Volatility,Model1)

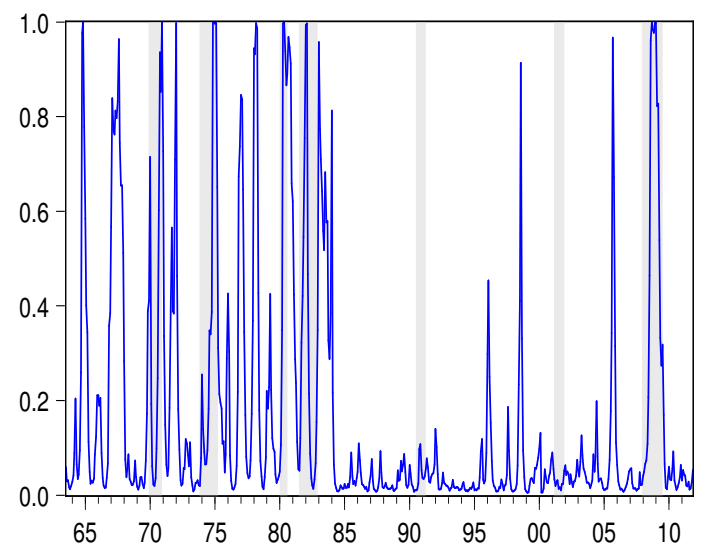

Prob (High Volatility,Model3)

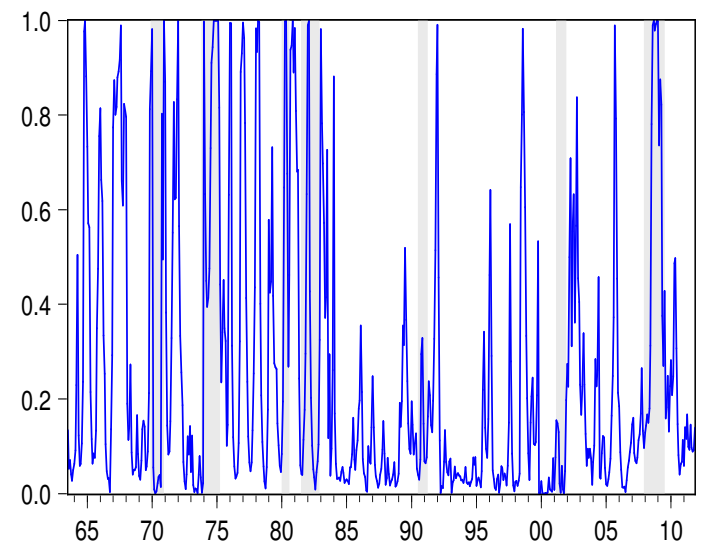

Prob (High Volatility,Model2)

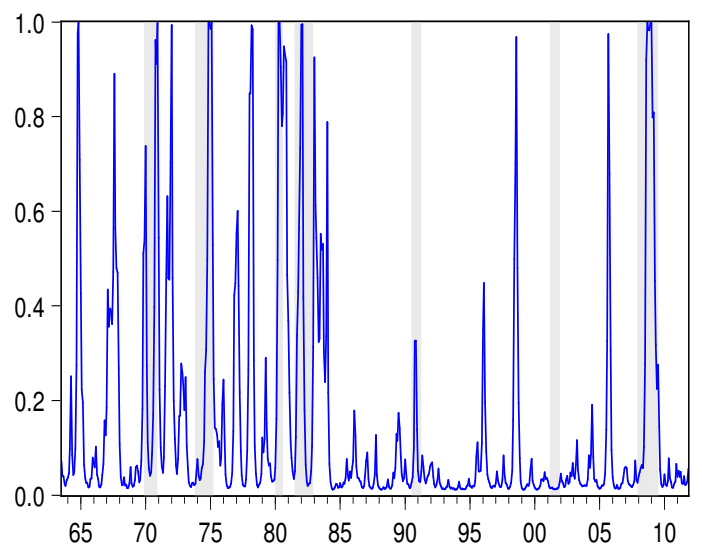

Prob (High Volatility,Model4)

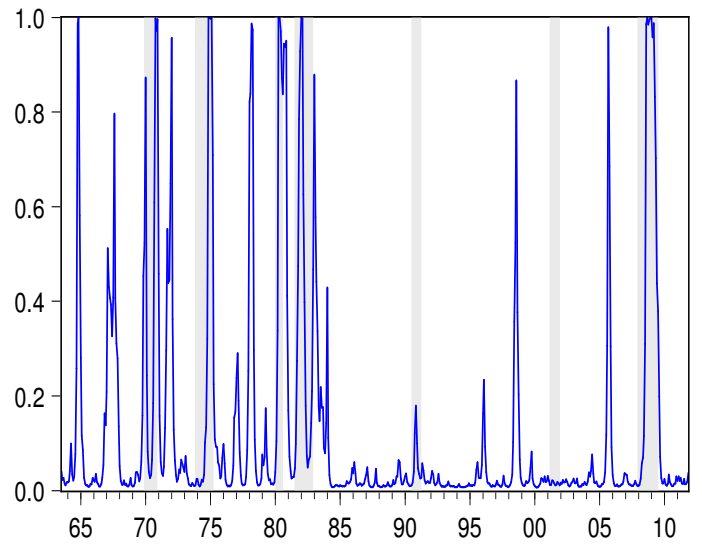

This figure plots the time-series of smoothed probabilities of high volatility regimes from four models defined in the section 2. Prob (High Volatility) is the unconditional probability of being in a high volatility regime, calculated by summing the probability of being in a high volatility regime and high mean regime, and the probability of being in a high volatility regime and low mean regime. The shaded lines in the plot correspond to NBER recession dates. The data are monthly and span the period from 1963:07 to 2011:11.

Figure 6: Smoothed Probabilities of High Volatility regimes (1963:07 - 2011:11) 
Prob (Recession,Model1)

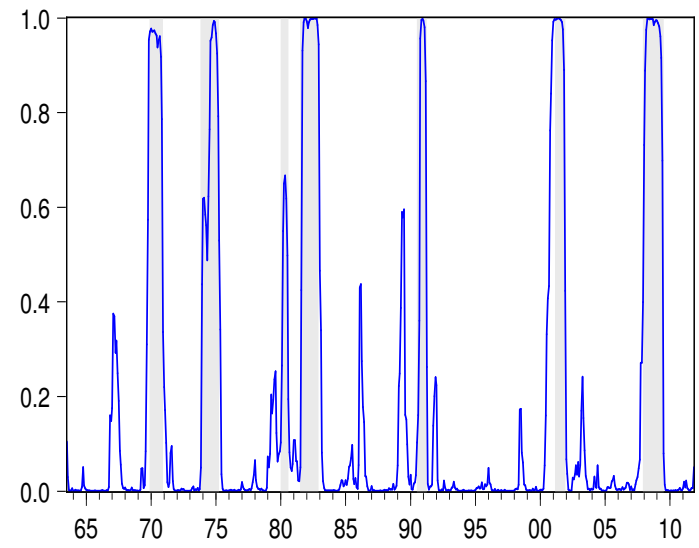

Prob (Recession,Model3)

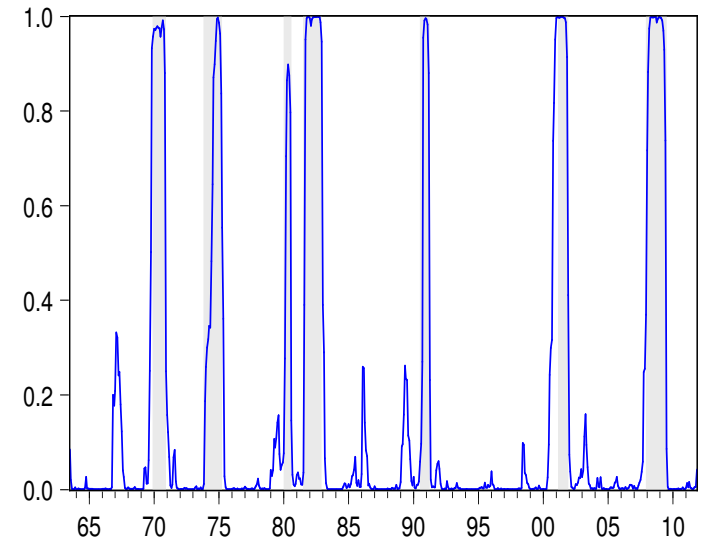

Prob (Recession,Model2)

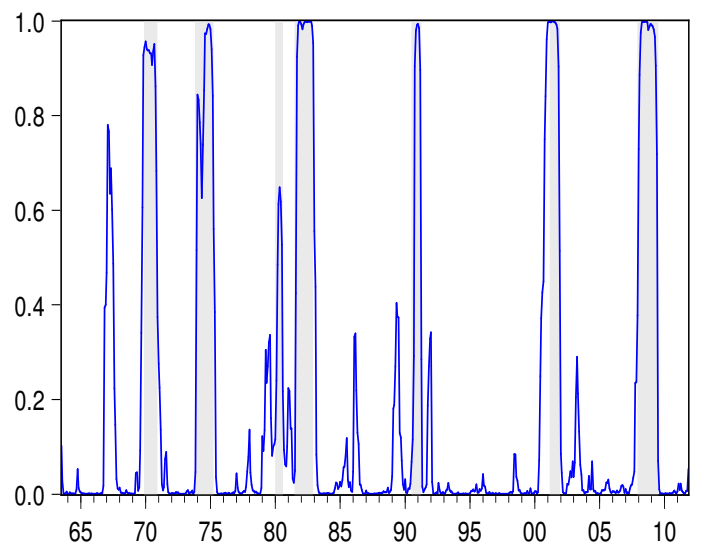

Prob (Recession,Model4)

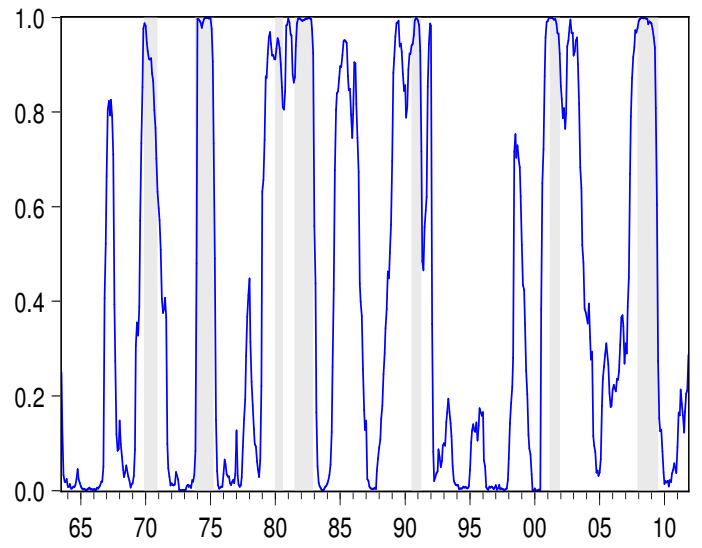

This figure plots the time-series of smoothed probabilities of recession regimes from four models defined in the section 2. Prob (Recession) is the unconditional probability of being in a low mean regime, calculated by summing the probability of being in a high volatility regime and low mean regime, and the probability of being in a low volatility regime and low mean regime. The shaded lines in the plot correspond to NBER recession dates. The data are monthly and span the period from 1963:07 to 2011:11.

Figure 7: Smoothed Probabilities of Recession regimes (1963:07 - 2011:11) 


\section{Table 1: Descriptive Statistics}

Summary statistics for the Fama-French three factors and the growth rates of the industrial production (Panel A: 1926:07 - 2011:11, Panel B: 1963:07 - 2011:11). The Auto(1) give the first autocorrelation. Note: The Fama-French three factors (RMRF, SMB, HML) are from Kenneth French's Web site. I define the growth rate of industrial production (INDG, annualized percentage data) as log differenced series of the index of industry production from the Federal Reserve Bank of St. Louis.

Panel A. the Whole Sample period (1926:07 - 2011:11)

\begin{tabular}{r|cccc}
\hline & RMRF & SMB & HML & INDG \\
\hline Mean & 0.62 & 0.24 & 0.38 & 3.14 \\
Std. Dev. & 5.46 & 3.32 & 3.57 & 21.91 \\
Skewness & 0.17 & 2.18 & 1.83 & 0.35 \\
Kurtosis & 10.39 & 25.12 & 18.59 & 17.29 \\
Auto(1) & 0.12 & 0.07 & 0.19 & 0.53 \\
\hline
\end{tabular}

Panel B. the Subsample period (1963:07 - 2011:11)

\begin{tabular}{r|cccc}
\hline & RMRF & SMB & HML & INDG \\
\hline Mean & 0.44 & 0.26 & 0.38 & 2.60 \\
Std. Dev. & 4.54 & 3.16 & 2.92 & 9.12 \\
Skewness & -0.53 & 0.52 & -0.01 & -0.98 \\
Kurtosis & 4.94 & 8.47 & 5.49 & 7.52 \\
Auto(1) & 0.09 & 0.06 & 0.16 & 0.33 \\
\hline
\end{tabular}


Table 2: A Markov Switching Model for the Growth Rate of Industrial Production

This table reports the maximum likelihood estimates of the model (Panel A: 1926:07 - 2011:11, Panel B: 1963:07 - 2011:11):

$$
\Delta y_{t}=\mu\left(S_{t}\right)+\varepsilon_{t}, \varepsilon_{t} \sim N\left(0, \sigma^{2}\left(V_{t}\right)\right)
$$

where $\Delta y_{t}$ are monthly growth rates of the industrial production. $S_{t}$ and $V_{t}$ are latent state variables for the regimes of mean and variance. I assume that the probability of changing mean regimes is independent of the probability of changing volatility regimes. It follows that there are two mean regimes, $\mu_{t} \equiv \mu\left(S_{t}\right) \in\left\{\mu_{l}, \mu_{h}\right\}$ and two volatility regimes, $\sigma_{t} \equiv \sigma\left(V_{t}\right) \in\left\{\sigma_{l}, \sigma_{h}\right\}$, where $l$ denotes the low regime and $h$ the high regime. I denote the transition probabilities of the Markov chains.

$$
\begin{aligned}
& P\left(\mu_{t}=\mu_{h} \mid \mu_{t-1}=\mu_{h}\right)=p_{h h}^{\mu}, P\left(\mu_{t}=\mu_{l} \mid \mu_{t-1}=\mu_{l}\right)=p_{l l}^{\mu} \\
& P\left(\sigma_{t}=\sigma_{h} \mid \sigma_{t-1}=\sigma_{h}\right)=p_{h h}^{\sigma}, P\left(\sigma_{t}=\sigma_{l} \mid \sigma_{t-1}=\sigma_{l}\right)=p_{l l}^{\sigma}
\end{aligned}
$$

Panel A. the Whole Sample period (1926:07 - 2011:11)

\begin{tabular}{c|crrrcccc}
\hline & $\mu_{h}$ & $\mu_{l}$ & $\sigma_{h}^{2}$ & $\sigma_{l}^{2}$ & $p_{h h}^{\mu}$ & $p_{l l}^{\mu}$ & $p_{h h}^{\sigma}$ & $p_{l l}^{\sigma}$ \\
\hline & 5.30 & -9.94 & 40.27 & 7.56 & 0.97 & 0.87 & 0.93 & 0.98 \\
t-stat & 14.83 & -6.63 & 19.13 & 29.25 & 124.93 & 28.24 & 46.98 & 180.07 \\
\hline
\end{tabular}

Panel B. the Subsample period (1963:07 - 2011:11)

\begin{tabular}{c|cccccccc}
\hline & $\mu_{h}$ & $\mu_{l}$ & $\sigma_{h}^{2}$ & $\sigma_{l}^{2}$ & $p_{h h}^{\mu}$ & $p_{l l}^{\mu}$ & $p_{h h}^{\sigma}$ & $p_{l l}^{\sigma}$ \\
\hline & 4.57 & -5.36 & 15.51 & 5.47 & 0.98 & 0.88 & 0.72 & 0.95 \\
t-stat & 12.51 & -4.67 & 8.00 & 17.16 & 97.96 & 22.02 & 8.55 & 49.70 \\
\hline
\end{tabular}


Table 3: A Simple Asset Pricing test for SMB

This table reports asset pricing test results to investigate if SMB is redundant given other Fama-French factors (RMRF, HML) (Panel A: 1926:07 - 2011:11, Panel B: 1963:07 - 2011:11):

$$
R_{s m b, t}=\alpha_{i}+\beta_{s m b}\left(R_{m t}-R_{f t}\right)+h_{s m b}\left(R_{h m l, t}\right)+\varepsilon_{t}
$$

where $R_{s m b, t}$ is the return to the SMB, $R_{m t}-R_{f t}$ is the market portfolio excess return, $R_{h m l, t}$ is the return on the HML. The Fama-French three factors (RMRF, SMB, HML) are from Kenneth French's Web site. I use Newey-West standard errors.

\begin{tabular}{c|ccc}
\multicolumn{5}{c}{ Panel A. the Whole Sample period $(1926: 07-2011: 11)$} \\
\hline & $\alpha_{i}$ & $\beta_{\text {smb }}$ & $h_{\text {smb }}$ \\
\hline & 0.11 & 0.20 & 0.02 \\
t-stat & 1.14 & 6.19 & 0.32 \\
\hline
\end{tabular}

Panel B. the Subsample period (1963:07 - 2011:11)

\begin{tabular}{c|ccc}
\hline & $\alpha_{i}$ & $\beta_{\text {smb }}$ & $h_{\text {smb }}$ \\
\hline \multirow{3}{*}{ t-stat } & 0.24 & 0.19 & -0.16 \\
& 1.72 & 4.89 & -1.31 \\
\hline
\end{tabular}


Table 4: A Simple Asset Pricing test for SMB with a Bivariate Regime Switching Model (Model 1)

This table reports asset pricing test results to investigate if SMB is redundant given other Fama-French factors (RMRF, HML). I estimate the following bivariate regime switching model to test the hypothesis (Panel A: 1926:07 - 2011:11, Panel B: 1963:07 - 2011:11).

$$
\begin{aligned}
& R_{s m b, t}=\alpha+\phi I\left(V_{t}=H\right)+\beta_{s m b}\left(R_{m t}-R_{f t}\right)+h_{s m b}\left(R_{h m l, t}\right)+\varepsilon_{s m b, t} \\
& \Delta y_{t}=\mu\left(S_{t}\right)+\varepsilon_{t}, \varepsilon_{t} \sim N\left(0, \sigma^{2}\left(V_{t}\right)\right), \varepsilon_{s m b, t} \sim N\left(0, \sigma^{2}\right)
\end{aligned}
$$

where $R_{s m b, t}$ is the return to the SMB, $R_{m t}-R_{f t}$ is the market portfolio excess return, $R_{h m l, t}$ is the return on the HML. The Fama-French three factors (RMRF, SMB, HML) are from Kenneth French's Web site. $I\left(V_{t}=H\right)$ is the indicator function having the value 1 for high-vol regimes and the value 0 for other regimes. $\Delta y_{t}$ is the monthly growth rate of the industrial production from the Federal Reserve Bank of St. Louis. $S_{t}$ and $V_{t}$ are latent state variables for the regimes of mean and variance. I assume that the probability of changing mean regimes is independent of the probability of changing volatility regimes. It follows that there are two mean regimes, $\mu_{t} \equiv \mu\left(S_{t}\right) \in\left\{\mu_{l}, \mu_{h}\right\}$ and two volatility regimes, $\sigma_{t} \equiv \sigma\left(V_{t}\right) \in\left\{\sigma_{l}, \sigma_{h}\right\}$, where $l$ denotes the low regime and $h$ the high regime. I denote the transition probabilities of the Markov chains.

$$
\begin{aligned}
& P\left(\mu_{t}=\mu_{h} \mid \mu_{t-1}=\mu_{h}\right)=p_{h h}^{\mu}, P\left(\mu_{t}=\mu_{l} \mid \mu_{t-1}=\mu_{l}\right)=p_{l l}^{\mu} \\
& P\left(\sigma_{t}=\sigma_{h} \mid \sigma_{t-1}=\sigma_{h}\right)=p_{h h}^{\sigma}, P\left(\sigma_{t}=\sigma_{l} \mid \sigma_{t-1}=\sigma_{l}\right)=p_{l l}^{\sigma}
\end{aligned}
$$

\begin{tabular}{|c|c|c|c|c|c|c|c|c|}
\hline & $\mu_{h}$ & $\mu_{l}$ & $\sigma_{h}^{2}$ & $\sigma_{l}^{2}$ & $p_{h h}^{\mu}$ & $p_{l l}^{\mu}$ & $p_{h h}^{\sigma}$ & $p_{l l}^{\sigma}$ \\
\hline & 5.31 & -9.99 & 40.47 & 7.58 & 0.97 & 0.87 & 0.93 & 0.98 \\
\hline \multirow[t]{3}{*}{ t-stat } & 14.96 & -6.98 & 19.25 & 30.41 & 123.32 & 28.31 & 45.35 & 178.21 \\
\hline & $\alpha$ & $\phi_{\text {high-vol }}$ & $\beta_{s m b}$ & $h_{s m b}$ & $\sigma$ & & & \\
\hline & -0.03 & 0.64 & 0.20 & 0.02 & 3.12 & & & \\
\hline t-stat & -0.62 & 2.78 & 10.49 & 0.65 & 45.24 & & & \\
\hline
\end{tabular}

Panel A. the Whole Sample period (1926:07 - 2011:11)

Panel B. the Subsample period (1963:07 - 2011:11)

\begin{tabular}{c|cccccccc}
\hline & $\mu_{h}$ & $\mu_{l}$ & $\sigma_{h}^{2}$ & $\sigma_{l}^{2}$ & $p_{h h}^{\mu}$ & $p_{l l}^{\mu}$ & $p_{h h}^{\sigma}$ & $p_{l l}^{\sigma}$ \\
\hline & 4.52 & -5.42 & 15.04 & 5.42 & 0.98 & 0.88 & 0.75 & 0.95 \\
t-stat & 12.66 & -4.73 & 9.29 & 19.02 & 98.43 & 21.46 & 10.02 & 54.22 \\
\hline & $\alpha$ & $\phi_{\text {high-vol }}$ & $\beta_{\text {smb }}$ & $h_{\text {smb }}$ & $\sigma$ & & & \\
\hline & \multicolumn{1}{|c}{} & & & & & & \\
\hline & 0.05 & 1.11 & 0.19 & -0.16 & 2.93 & & & \\
t-stat & 0.39 & 2.21 & 6.70 & -3.67 & 33.04 & & & \\
\hline
\end{tabular}


Table 5: A Simple Asset Pricing test for SMB with a Bivariate Regime Switching Model (Model 2)

This table reports asset pricing test results to investigate if SMB is redundant given other Fama-French factors (RMRF, HML). I estimate the following bivariate regime switching model to test the hypothesis (Panel A: 1926:07 - 2011:11, Panel B: 1963:07 - 2011:11).

$$
\begin{aligned}
& R_{s m b, t}=\alpha+\lambda I\left(S_{t}=L\right)+\beta_{s m b}\left(R_{m t}-R_{f t}\right)+h_{s m b}\left(R_{h m l, t}\right)+\varepsilon_{s m b, t} \\
& \Delta y_{t}=\mu\left(S_{t}\right)+\varepsilon_{t}, \varepsilon_{t} \sim N\left(0, \sigma^{2}\left(V_{t}\right)\right), \varepsilon_{s m b, t} \sim N\left(0, \sigma^{2}\right)
\end{aligned}
$$

where $R_{s m b, t}$ is the return to the SMB, $R_{m t}-R_{f t}$ is the market portfolio excess return, $R_{h m l, t}$ is the return on the HML. The Fama-French three factors (RMRF, SMB, HML) are from Kenneth French's Web site. $I\left(S_{t}=L\right)$ is the indicator function having the value 1 for low-mean (recession) regimes and the value 0 for other regimes. $\Delta y_{t}$ is the monthly growth rate of the industrial production from the Federal Reserve Bank of St. Louis. $S_{t}$ and $V_{t}$ are latent state variables for the regimes of mean and variance. I assume that the probability of changing mean regimes is independent of the probability of changing volatility regimes. It follows that there are two mean regimes, $\mu_{t} \equiv \mu\left(S_{t}\right) \in\left\{\mu_{l}, \mu_{h}\right\}$ and two volatility regimes, $\sigma_{t} \equiv \sigma\left(V_{t}\right) \in\left\{\sigma_{l}, \sigma_{h}\right\}$, where $l$ denotes the low regime and $h$ the high regime. I denote the transition probabilities of the Markov chains.

$$
\begin{aligned}
& P\left(\mu_{t}=\mu_{h} \mid \mu_{t-1}=\mu_{h}\right)=p_{h h}^{\mu}, P\left(\mu_{t}=\mu_{l} \mid \mu_{t-1}=\mu_{l}\right)=p_{l l}^{\mu} \\
& P\left(\sigma_{t}=\sigma_{h} \mid \sigma_{t-1}=\sigma_{h}\right)=p_{h h}^{\sigma}, P\left(\sigma_{t}=\sigma_{l} \mid \sigma_{t-1}=\sigma_{l}\right)=p_{l l}^{\sigma}
\end{aligned}
$$

\begin{tabular}{|c|c|c|c|c|c|c|c|c|}
\hline & $\mu_{h}$ & $\mu_{l}$ & $\sigma_{h}^{2}$ & $\sigma_{l}^{2}$ & $p_{h h}^{\mu}$ & $p_{l l}^{\mu}$ & $p_{h h}^{\sigma}$ & $p_{l l}^{\sigma}$ \\
\hline & 5.30 & -9.99 & 40.27 & 7.56 & 0.97 & 0.87 & 0.93 & 0.98 \\
\hline \multirow[t]{2}{*}{ t-stat } & 14.55 & -6.24 & 18.56 & 26.11 & 95.74 & 24.57 & 24.95 & 83.86 \\
\hline & $\alpha$ & $\lambda_{\text {low-mean }}$ & $\beta_{s m b}$ & $h_{s m b}$ & $\sigma$ & & & \\
\hline & 0.08 & 0.15 & 0.20 & 0.02 & 3.13 & & & \\
\hline t-stat & 0.18 & 0.14 & 4.94 & 0.13 & 45.21 & & & \\
\hline
\end{tabular}

\begin{tabular}{|c|c|c|c|c|c|c|c|c|}
\hline & $\mu_{h}$ & $\mu_{l}$ & $\sigma_{h}^{2}$ & $\sigma_{l}^{2}$ & $p_{h h}^{\mu}$ & $p_{l l}^{\mu}$ & $p_{h h}^{\sigma}$ & $p_{l l}^{\sigma}$ \\
\hline & 4.60 & -5.29 & 15.68 & 5.47 & 0.98 & 0.88 & 0.71 & 0.95 \\
\hline t-stat & 12.60 & -4.77 & 8.01 & 17.28 & 93.01 & 21.60 & 8.43 & 50.42 \\
\hline & $\alpha$ & $\lambda_{\text {low-mean }}$ & $\beta_{s m b}$ & $h_{s m b}$ & $\sigma$ & & & \\
\hline & 0.12 & 0.66 & 0.19 & -0.16 & 2.95 & & & \\
\hline t-stat & 0.77 & 1.70 & 6.72 & -3.69 & 33.97 & & & \\
\hline
\end{tabular}

Panel A. the Whole Sample period (1926:07 - 2011:11)

Panel B. the Subsample period (1963:07 - 2011:11) 
Table 6: A Simple Asset Pricing test for SMB with a Bivariate Regime Switching Model (Model 3)

This table reports asset pricing test results to investigate if SMB is redundant given other Fama-French factors (RMRF, HML). I estimate the following bivariate regime switching model to test the hypothesis (Panel A: 1926:07 - 2011:11, Panel B: 1963:07 - 2011:11).

$$
\begin{aligned}
& R_{s m b, t}=\alpha+\phi I\left(V_{t}=H\right)+\left(\beta_{s m b}+\beta_{s m b} I\left(V_{t}=H\right)\right)\left(R_{m t}-R_{f t}\right)+\left(h_{s m b}+h_{s m b} I\left(V_{t}=H\right)\right)\left(R_{h m l, t}\right)+\varepsilon_{s m b, t} \\
& \Delta y_{t}=\mu\left(S_{t}\right)+\varepsilon_{t}, \varepsilon_{t} \sim N\left(0, \sigma^{2}\left(V_{t}\right)\right), \varepsilon_{s m b, t} \sim N\left(0, \sigma^{2}\right)
\end{aligned}
$$

where $R_{s m b, t}$ is the return to the SMB, $R_{m t}-R_{f t}$ is the market portfolio excess return, $R_{h m l, t}$ is the return on the HML. The Fama-French three factors (RMRF, SMB, HML) are from Kenneth French's Web site. $I\left(V_{t}=H\right)$ is the indicator function having the value 1 for high-vol regimes and the value 0 for other regimes. $\Delta y_{t}$ is the monthly growth rate of the industrial production from the Federal Reserve Bank of St. Louis. $S_{t}$ and $V_{t}$ are latent state variables for the regimes of mean and variance. I assume that the probability of changing mean regimes is independent of the probability of changing volatility regimes. It follows that there are two mean regimes, $\mu_{t} \equiv \mu\left(S_{t}\right) \in\left\{\mu_{l}, \mu_{h}\right\}$ and two volatility regimes, $\sigma_{t} \equiv \sigma\left(V_{t}\right) \in\left\{\sigma_{l}, \sigma_{h}\right\}$, where $l$ denotes the low regime and $h$ the high regime. I denote the transition probabilities of the Markov chains.

$$
\begin{aligned}
& P\left(\mu_{t}=\mu_{h} \mid \mu_{t-1}=\mu_{h}\right)=p_{h h}^{\mu}, P\left(\mu_{t}=\mu_{l} \mid \mu_{t-1}=\mu_{l}\right)=p_{l l}^{\mu} \\
& P\left(\sigma_{t}=\sigma_{h} \mid \sigma_{t-1}=\sigma_{h}\right)=p_{h h}^{\sigma}, P\left(\sigma_{t}=\sigma_{l} \mid \sigma_{t-1}=\sigma_{l}\right)=p_{l l}^{\sigma}
\end{aligned}
$$

\begin{tabular}{|c|c|c|c|c|c|c|c|c|}
\hline & $\mu_{h}$ & $\mu_{l}$ & $\overline{\sigma_{h}^{2}}$ & $\sigma_{l}^{2}$ & $p_{h h}^{\mu}$ & $p_{l l}^{\mu}$ & $\overline{p_{h h}^{\sigma}}$ & $\overline{p_{l l}^{\sigma}}$ \\
\hline \multirow{4}{*}{ t-stat } & 5.20 & -11.28 & 40.53 & 7.63 & 0.97 & 0.87 & 0.91 & 0.98 \\
\hline & 14.49 & -8.39 & 18.93 & 31.76 & 132.62 & 28.55 & 38.94 & 154.65 \\
\hline & $\alpha$ & $\phi_{\text {high-vol }}$ & $\beta_{s m b}$ & $\beta_{\text {smb,high-vol }}$ & $h_{s m b}$ & $h_{s m b, h i g h-v o l}$ & $\sigma$ & \\
\hline & 0.07 & 0.55 & 0.14 & 0.02 & -0.22 & 0.59 & 2.94 & \\
\hline t-stat & 1.09 & 2.44 & 5.70 & 0.49 & -6.11 & 10.00 & 44.47 & \\
\hline
\end{tabular}

\begin{tabular}{|c|c|c|c|c|c|c|c|c|}
\hline & $\mu_{h}$ & $\mu_{l}$ & $\overline{\sigma_{h}^{2}}$ & $\overline{\sigma_{l}^{2}}$ & $p_{h h}^{\mu}$ & $p_{l l}^{\mu}$ & $p_{h h}^{\sigma}$ & $p_{l l}^{\sigma}$ \\
\hline \multirow{4}{*}{ t-stat } & 4.50 & -6.07 & 12.84 & 5.09 & 0.98 & 0.90 & 0.72 & 0.90 \\
\hline & 14.36 & -6.18 & 11.33 & 17.38 & 129.04 & 24.10 & 10.31 & 27.65 \\
\hline & $\alpha$ & $\phi_{\text {high-vol }}$ & $\beta_{s m b}$ & $\beta_{s m b, h i g h-v o l}$ & $h_{s m b}$ & $h_{s m b, h i g h-v o l}$ & $\sigma$ & \\
\hline & 0.09 & 0.75 & 0.15 & 0.03 & -0.44 & 0.86 & 2.69 & \\
\hline t-stat & 0.59 & 1.95 & 3.76 & 0.46 & -6.88 & 8.23 & 30.83 & \\
\hline
\end{tabular}

Panel A. the Whole Sample period (1926:07 - 2011:11)

Panel B. the Subsample period (1963:07 - 2011:11) 
Table 7: A Simple Asset Pricing test for SMB with a Bivariate Regime Switching Model (Model 4)

This table reports asset pricing test results to investigate if SMB is redundant given other Fama-French factors (RMRF, HML). I estimate the following bivariate regime switching model to test the hypothesis (Panel A: 1926:07 - 2011:11, Panel B: 1963:07 - 2011:11).

$$
\begin{aligned}
& R_{s m b, t}=\alpha+\lambda I\left(S_{t}=L\right)+\left(\beta_{s m b}+\beta_{s m b} I\left(S_{t}=L\right)\right)\left(R_{m t}-R_{f t}\right)+\left(h_{s m b}+h_{s m b} I\left(S_{t}=L\right)\right)\left(R_{h m l, t}\right)+\varepsilon_{s m b, t} \\
& \Delta y_{t}=\mu\left(S_{t}\right)+\varepsilon_{t}, \varepsilon_{t} \sim N\left(0, \sigma^{2}\left(V_{t}\right)\right), \varepsilon_{s m b, t} \sim N\left(0, \sigma^{2}\right)
\end{aligned}
$$

where $R_{s m b, t}$ is the return to the SMB, $R_{m t}-R_{f t}$ is the market portfolio excess return, $R_{h m l, t}$ is the return on the HML. The Fama-French three factors (RMRF, SMB, HML) are from Kenneth French's Web site. $I\left(S_{t}=L\right)$ is the indicator function having the value 1 for low-mean (recession) regimes and the value 0 for other regimes. $\Delta y_{t}$ is the monthly growth rate of the industrial production from the Federal Reserve Bank of St. Louis. $S_{t}$ and $V_{t}$ are latent state variables for the regimes of mean and variance. I assume that the probability of changing mean regimes is independent of the probability of changing volatility regimes. It follows that there are two mean regimes, $\mu_{t} \equiv \mu\left(S_{t}\right) \in\left\{\mu_{l}, \mu_{h}\right\}$ and two volatility regimes, $\sigma_{t} \equiv \sigma\left(V_{t}\right) \in\left\{\sigma_{l}, \sigma_{h}\right\}$, where $l$ denotes the low regime and $h$ the high regime. I denote the transition probabilities of the Markov chains.

$$
\begin{aligned}
& P\left(\mu_{t}=\mu_{h} \mid \mu_{t-1}=\mu_{h}\right)=p_{h h}^{\mu}, P\left(\mu_{t}=\mu_{l} \mid \mu_{t-1}=\mu_{l}\right)=p_{l l}^{\mu} \\
& P\left(\sigma_{t}=\sigma_{h} \mid \sigma_{t-1}=\sigma_{h}\right)=p_{h h}^{\sigma}, P\left(\sigma_{t}=\sigma_{l} \mid \sigma_{t-1}=\sigma_{l}\right)=p_{l l}^{\sigma}
\end{aligned}
$$

Panel A. the Whole Sample period (1926:07 - 2011:11)

\begin{tabular}{r|rrrrrrrr}
\hline & $\mu_{h}$ & $\mu_{l}$ & $\sigma_{h}^{2}$ & $\sigma_{l}^{2}$ & $p_{h h}^{\mu}$ & $p_{l l}^{\mu}$ & $p_{h h}^{\sigma}$ & $p_{l l}^{\sigma}$ \\
\hline & 5.53 & -5.94 & 40.22 & 7.21 & 0.94 & 0.80 & 0.93 & 0.98 \\
t-stat & 13.15 & -3.73 & 19.88 & 22.70 & 59.43 & 14.86 & 48.35 & 134.07 \\
\hline \multicolumn{2}{r}{} & & & & & & & \\
\hline & $\alpha$ & $\lambda_{\text {low-mean }}$ & $\beta_{\text {smb }}$ & $\beta_{\text {smb,low-mean }}$ & $h_{\text {smb }}$ & $h_{\text {smb,low-mean }}$ & $\sigma$ \\
\hline \multirow{2}{*}{ t-stat } & 0.04 & 0.39 & 0.15 & 0.09 & -0.24 & 0.72 & 2.82 \\
& 0.30 & 1.09 & 5.51 & 1.35 & -5.94 & 9.14 & 40.77 \\
\hline
\end{tabular}

Panel B. the Subsample period (1963:07 - 2011:11)

\begin{tabular}{r|rrrrrrrr}
\hline & $\mu_{h}$ & $\mu_{l}$ & $\sigma_{h}^{2}$ & $\sigma_{l}^{2}$ & $p_{h h}^{\mu}$ & $p_{l l}^{\mu}$ & $p_{h h}^{\sigma}$ & $p_{l l}^{\sigma}$ \\
\hline & 5.73 & -0.88 & 17.80 & 5.73 & 0.96 & 0.93 & 0.73 & 0.96 \\
t-stat & 9.14 & -0.71 & 8.82 & 21.58 & 51.74 & 30.50 & 9.96 & 71.26 \\
\hline
\end{tabular}

\begin{tabular}{r|rrrrrrr}
\hline & $\alpha$ & $\lambda_{\text {low-mean }}$ & $\beta_{\text {smb }}$ & $\beta_{\text {smb }, \text { low-mean }}$ & $h_{\text {smb }}$ & $h_{\text {smb }, \text { low-mean }}$ & $\sigma$ \\
\hline & 0.25 & 0.05 & 0.21 & -0.02 & -0.40 & 0.49 & 2.87 \\
t-stat & 1.86 & 0.42 & 5.43 & -0.41 & -4.89 & 4.66 & 32.58 \\
\hline
\end{tabular}

